Pacific Journal of 


\title{
WEAK HOMOMORPHISMS AND INVARIANTS:
} AN EXAMPLE

\author{
ANDREW ADLER
}

\begin{abstract}
Notions of weak isomorphism, weak epimorphism, and weak embedding are defined. For countable algebras, these specialize to the ordinary notions. Certain invariants for superatomic Boolean algebras are described. It is shown that the existence or non-existence of weak isomorphisms, weak epimorphisms, and weak embeddings between two such algebras $A$ and $B$ can be decided from the invariants of $A$ and $B$.
\end{abstract}

I. Introduction. In [4], Day described certain invariants for superatomic Boolean algebras that refine invariants first introduced by Mazurkiewicz and Sierpinski [6]. Day showed using topological methods that any two countable superatomic Boolean algebras with the same invariants are isomorphic. In [3], Cramer described a partial order $\leqq$ on the Day invariants. He showed, again using topological methods, that the countable algebra $A$ is embeddable in $B$ if and only if the Day invariant of $A$ is $\leqq$ the Day invariant of $B$, and that the countable algebra $B$ is a homomorphic image of the countable algebra $A$ if and only if the invariant of $A$ is $\geqq$ the invariant of $B$. Day and Cramer give examples that show the countability assumptions cannot be dropped.

In this paper, we describe notions of weak isomorphism, weak embedding and weak epimorphism that have already been used with success in the study of Abelian torsion groups [2]. We then show that for any two superatomic Boolean algebras $A$ and $B, A$ is weakly isomorphic to $B$ iff $A$ and $B$ have the same Mazurkiewicz-Sierpinski invariant, $A$ is weakly embeddable in $B$ iff the invariant of $A$ is $\leqq$ the invariant of $B$, and $B$ is a weak image of $A$ iff the invariant of $A$ is $\geqq$ the invariant of $B$. From these results it is in particular easy to derive the results of Day and Cramer mentioned above.

The motivation for looking at the subject came from infinitary logic, and our first proof of the main result used a certain amount of machinery from that subject. The proof we present here, however, uses only a little elementary algebra. There is a good deal of evidence (see Barwise [1]) that the notion of weak isomorphism is algebraically more natural and better behaved that the notion of isomorphism. Our main result will add a little to that evidence.

II. Weak homomorphisms. Let $A, B$ be algebraic structures 
of the same type (so $A$ and $B$ are both groups, or both ordered fields, or both $R$-modules, $\cdots$ ).

Definition. A weak homomorphism from $A$ into $B$ is a nonempty collection $\Phi$ of maps such that: (i) For any $\phi \in \Phi$, the domain of $\phi$ is a substructure of $A$, the range of $\operatorname{rng}(\phi)$ is a substructure of $B$, and $\phi$ is a homomorphism from $\operatorname{dom}(\phi)$. (ii) (The extendability property.) For any $a \in A$ and any $\dot{\phi} \in \Phi$, there exists $\phi^{\prime} \in \Phi$ such that $\phi^{\prime}$ is an extension of $\phi$ and $a \in \operatorname{dom}\left(\phi^{\prime}\right)$. If in addition for every $b \in B$ and $\phi \in \Phi$ there $\phi^{\prime} \in \Phi$ such that is $\phi^{\prime}$ extends $\phi$ and $b \in \operatorname{rng}\left(\phi^{\prime}\right)$, $\Phi$ is a weak epimorphism. If every $\phi$ in the weak epimorphism $\Phi$ is one-to-one, $\Phi$ is a weak embedding. If $\Phi$ is at once a weak epimorphism and a weak embedding, $\Phi$ is a weak isomorphism.

The notion of weak isomorphism goes back to Karp [5]. Notions very close to our notion of weak epimorphism and weak embedding have been used in [2]. At the cost of complicating the definition somewhat, we could make weak homomorphisms into genuine morphisms in the sense of category theory. Since this would not change the mathematical content of the main result, we will stay with the simple definitions given above.

The following result in principle goes back to Cantor. Part (ii) is done by a simple "back and forth" or "zipper" argument. Part (i) is even simpler.

Lemma 1. (i) If $A$ is countably generated, and $A$ is weakly embeddable in $B$, then $A$ is embeddable in $B$. (ii) If $A$ and $B$ are countably generated, and $A$ is weakly isomorphic to $B$ (respectively: is a weak homomorphic image of $B$ ) then $A$ and $B$ are isomorphic (respectively: $A$ is a homomorphic image of $B$ ).

III. Superatomic Boolean algebras-the invariants. Let $B$ be a superatomic Boolean algebra, that is, a Boolean algebra $B$ such that every homormophic image of $B$ is atomic. Define a sequence $I_{0}, I_{1}, \ldots$ of ideals of $B$ by the following rules:

(i) $I_{0}=(0)$. (ii) If $\beta=\alpha+1$, let $I$ be the ideal of $B / I_{\alpha}$ generated by the atoms of $B / I_{\alpha}$. Let $I_{\beta}$ be the set of preimages in $B$ of elements of $I$. (iii) If $\beta$ is a limit ordinal, let $I_{\beta}=\bigcup_{\alpha<\beta} I_{\alpha}$.

Because $B$ is superatomic, there is a first ordinal $\alpha$ such that $I_{\alpha}=B$ (see Day [4]). $\alpha$ is necessarily a successor ordinal. Let $\rho=\rho(B)$ be the greatest ordinal such that $I_{\rho} \neq B$. Then $B / I_{\rho}$ has a finite number $n(B)$ of atoms.

For any nonzero $b \in B$, let $\rho(b)$ (the rank of $b$ ) be the greatest ordinal such that $b \notin I_{\rho}$. So $\rho(B)=\rho(1)$, where 1 is the unit of the algebra $B$. If $b \neq 0, b$ is the preimage in $B$ of an object which is 
a finite join of atoms of $B / I_{\rho}$. Let $n(b)$ be the number of atoms used in this representation. So $n(b)$ is a positive integer, and $n(B)=u(1)$. Let $s(b)$ be the ordered pair $(\rho(b), n(b))$. For completeness, let $s(0)=(0,0)$. Let $s(B)=s(1)$. Let $\leqq$ be the lexicographic order on pairs of the form $(\rho, n)$. The following is an easy consequence of the definitions:

LEMMA 2. (i) $\rho(a \vee b)=\max (\rho(a), \rho(b))$. (ii) If $\rho(a)=\rho(b)$ and $\rho(a \wedge b)<\rho(a)$, then $n(a \vee b)=n(a)+n(b)$. If $\rho(a)<\rho(b)$ then $n(a \vee b)=n(b)$

So in particular, if $B_{f}$ is a finite subalgebra of $B$, then $s(b)$ can be easily computed for every $b \in B_{f}$ if we know $s(a)$ for every atom $a$ of $B_{f}$. In what follows, we will make use also of the following observation:

Lemma 3. Let $b \in B$, and suppose $(\rho, n) \leqq s(b)$. Then there exists $a \subseteq b$ such that $s(a)=(\rho, n)$.

Lemma 4. Let $A, B$ be superatomic Boolean algebras. Let $u \in A$, $v \in B$, with $s(u) \leqq s(v)$. (i) Let $u=u_{1} \vee u_{2}$, with $u_{1} \wedge u_{2}=0$. Then there exist $v_{1}, v_{2} \in B$, with $v=v_{1} \vee v_{2}, v_{1} \wedge v_{2}=0$, and $s\left(u_{1}\right) \leqq s\left(v_{1}\right)$, $s\left(u_{2}\right) \leqq s\left(v_{2}\right)$. If $s(u)=s(v)$, then $v_{1}, v_{2}$ may be chosen so that $s\left(u_{1}\right)=$ $s\left(v_{1}\right), \quad s\left(u_{2}\right)=s\left(v_{2}\right)$. (ii) Let $v=v_{1} \vee v_{2}$, with $v_{1} \wedge v_{2}=0$. Then there exist $u_{1}, u_{2} \in A$, with $u=u_{1} \vee u_{2}, u_{1} \wedge u_{2}=0$, and $s\left(u_{1}\right) \leqq s\left(v_{1}\right)$, $s\left(u_{2}\right) \leqq s\left(v_{2}\right)$.

Proof. We prove (i). Suppose $s\left(u_{1}\right) \leqq s\left(u_{2}\right)$. Choose $v_{1} \subseteq v$ so that $s\left(u_{1}\right)=s\left(v_{1}\right)$. Let $v_{2}=v-v_{1}$. By Lemma 2, $s\left(u_{2}\right) \leqq s\left(v_{2}\right)$, and if $s(u)=s(v), s\left(u_{2}\right)=s\left(v_{2}\right)$.

IV. Weak homomorphisms and the invariants. In this section we show that the existence of weak isomorphisms (weak epimorphisms, weak embeddings) between superatomic algebras $A$ and $B$ depends only on the invariants of $A$ and $B$.

Lemma 5. Let $\Phi$ be a weak homomorphism of $A$ into $B$. Let $\phi \in \Phi$, and let $a \in \operatorname{dom}(\phi)$. If $\Phi$ is a weak embedding, $s(a) \leqq s(\phi a)$. If $\Phi$ is a weak epimorphism, $s(a) \geqq s(\phi a)$. In particular, if $\Phi$ is a weak isomorphism, $s(a)=s(\phi a)$.

Proof. We deal with the case that $\Phi$ is a weak embedding. For weak epimorphisms essentially the same argument will do. We proceed by induction on the well-ordering $\leqq$. Now $s(\alpha)=(0,1)$ iff 
$a$ is an atom of $A$. But then $\phi a \neq 0$, so $s(a) \leqq s(\phi a)$. Suppose now $\rho(a)=\rho$ and $n(a)>1$. Then by Lemma 3 one can find disjoint elements $c, d \in A$ such that $a=c \vee d, \rho(c)=\rho(d)=\rho, n(c)=n(a)-1$, $n(d)=1$. Let $\phi^{\prime} \in \Phi$ be an extension of $\phi$ that has $c, d$ in its domain. By induction hypothesis, $s(c) \leqq s\left(\phi^{\prime} c\right), \quad s(d) \leqq s\left(\phi^{\prime} d\right)$, and so easily $s(a) \leqq s\left(\phi^{\prime} a\right)=s(\phi a)$. If $n(a)=1$, then for every $(\rho, n)<s(a)$ there exists $c \leqq a$ such that $s(c)=(\rho, n)$. Let $\phi^{\prime} \in \Phi$ extend $\phi$ to $c$. Then $(\rho, n) \leqq s\left(\phi^{\prime} c\right) \leqq s\left(\phi^{\prime} a\right)=s(\phi a)$. So for any $(\rho, n)<s(\alpha),(\rho, n)<s(\phi a)$. Hence $s(a) \leqq s(\phi a)$.

Theorem. Let $A, B$ be superatomic Boolean algebras. Then (i) $A$ is a weakly embeddable in $B$ iff $s(A) \leqq s(B)$. (ii) $B$ is a weak homomorphic image of $A$ iff $s(A) \geqq s(B)$. (iii) $A$ and $B$ are weakly isomorphic iff $s(A)=s(B)$.

Proof. In one direction, everything is settled by Lemma 5 . We prove now that if $s(A)=s(B), A$ and $B$ are weakly isomorphic. The arguments for (i) and (ii) are essentially the same as those for (iii).

So suppose $s(A)=s(B)$. Let $\Phi$ be the set of all maps $\phi$ such that:

(a) $\operatorname{dom}(\phi)$ is a finite subalgebra of $A$, rng $(\phi)$ is a finite subalgebra of $B$, and $\phi$ is an isomorphism of $\operatorname{dom}(\phi)$ and $\operatorname{rng}(\phi)$.

(b) For any $a \in \operatorname{dom}(\phi), s(a)=s(\phi \alpha)$.

We prove that $\Phi$ is a weak isomorphism from $A$ to $B$. $\Phi$ is nonempty for since $s(A)=s(B)$, the map that sends 0 to 0 and 1 to 1 belongs to $\phi$. Let $\phi \in \Phi$ and let $a \in A$. We wish to find $\phi^{\prime} \in \Phi$ such that $\phi^{\prime}$ extends $\phi$ and $a \in \operatorname{dom}\left(\phi^{\prime}\right)$. Let $A_{0}=\operatorname{dom}(\phi), B_{0}=\operatorname{rng}(\phi)$. Using Lemma 4, choose $v_{j}^{1}, v_{j}^{2}$ so that $v_{j}=v_{j}^{1} \vee u_{j}^{2}, u_{j}^{1} \wedge v_{j}^{2}=0$, and $s\left(u_{j}^{i}\right)=s\left(v_{j}^{i}\right)$. Let $B_{1}$ be the subalgebra of $B$ generated by the $v_{j}^{i}$. Let $u_{1}, \cdots, u_{k}$ be the atoms of $A_{0}$, and let $v_{j}=\phi u_{j}$. Let $u_{j}^{1}=u_{j} \wedge a$, $u_{j}^{2}=u_{j} \wedge a^{\prime}$. Let $A_{1}$ be the subalgebra of $A$ generated by the $u_{j}^{i}$. The map that sends $u_{j}^{i}$ into $v_{j}^{i}$ extends to an isomorphism $\phi^{\prime}$ of $A_{1}$ to $B_{1}$ which extends $\phi$. Lemma 2 easily yields that $\phi^{\prime} \in \Phi$. In exactly the same way, if $b \in B$ one can find an extension $\phi^{\prime}$ of $\phi$ such that $b \in \operatorname{rng}\left(\phi^{\prime}\right)$.

Conollary. (i) (Day [4]). If $A$ and $B$ are countable and $s(A)=s(B), A$ and $B$ are isomorphic. (ii) (Cramer [3]). If $A$ is countable and $s(A) \leqq s(B), A$ is embeddable in $B$. If $A$ and $B$ are countable and $s(A) \leqq s(B), A$ is a homomorphic image of $B$.

Proof. The result follows immediately from the previous theorem and Lemma 1. 


\section{REFERENCES}

1. J. Barwise, Back and forth through infinitary logic, in Studies in Model Theory, M.A.A. (1973), 5-34.

2. J. Barwise and P. Eklof, Infinitary properties of Abelian torsion groups, Annals of Math. Logic, 2 (1970), 25-68.

3. T. Cramer, Countable Boolean algebras as subalgebras and homomorphs, Pacific J. Math., 35 (1970), 321-326.

4. G. W. Day, Superatomic Boolean algebras, Pacific J. Math., 23 (1967), 479-489.

5. C. Karp, Languages with Expressions of Infinite Length, North-Holland Publishing Company, Amsterdam 1964.

6. S. Mazurkiewicz and W. Sierpinski, Contributions a la topologie des ensembles denombrables, Fund. Math., 1 (1920), 17-27.

Received July 16, 1975.

UNIVERSITY OF BRITISH COLUMBIA 



\section{PACIFIC JOURNAL OF MATHEMATICS}

\section{EDITORS}

RICHARD ARENS (Managing Editor)

University of California

Los Angeles, California 90024

\section{R. A. Beaumont}

University of Washington

Seattle, Washington 98105
J. DugundjI

Department of Mathematics

University of Southern California

Los Angeles, California 90007

D. Gilbarg and J. Milgram

Stanford University

Stanford, California 94305

\section{ASSOCIATE EDITORS}
E. F. BECKENBACH
B. H. NeumanN
F. WOLF
K. YosHIDA

\section{SUPPORTING INSTITUTIONS}

\author{
UNIVERSITY OF BRITISH COLUMBIA \\ CALIFORNIA INSTITUTE OF TECHNOLOGY \\ UNIVERSITY OF CALIFORNIA \\ MONTANA STATE UNIVERSITY \\ UNIVERSITY OF NEVADA \\ NEW MEXICO STATE UNIVERSITY \\ OREGON STATE UNIVERSITY \\ UNIVERSITY OF OREGON \\ OSAKA UNIVERSITY
}

\author{
UNIVERSITY OF SOUTHERN CALIFORNIA \\ STANFORD UNIVERSITY \\ UNIVERSITY OF HAWAII \\ UNIVERSITY OF TOKYO \\ UNIVERSITY OF UTAH \\ WASHINGTON STATE UNIVERSITY \\ UNIVERSITY OF WASHINGTON \\ AMERICAN MATHEMATICAL SOCIETY
}

The Supporting Institutions listed above contribute to the cost of publication of this Journal, but they are not owners or publishers and have no responsibility for its content or policies.

Mathematical papers intended for publication in the Pacific Journal of Mathematics should be in typed form or offset-reproduced, (not dittoed), double spaced with large margins. Please do not use built up fractions in the text of your manuscript. You may however, use them in the displayed equations. Underline Greek letters in red, German in green, and script in blue. The first paragraph or two must be capable of being used separately as a synopsis of the entire paper. Items of the bibliography should not be cited there unless absolutely necessary, in which case they must be identified by author and Journal, rather than by item number. Manuscripts, in triplicate, may be sent to any one of the editors. Please classify according to the scheme of Math. Reviews, Index to Vol. 39. All other communications should be addressed to the managing editor, or Elaine Barth, University of California, Los Angeles, California, 90024.

The Pacific Journal of Mathematics expects the author's institution to pay page charges, and reserves the right to delay publication for nonpayment of charges in case of financial emergency.

100 reprints are provided free for each article, only if page charges have been substantially paid. Additional copies may be obtained at cost in multiples of 50 .

The Pacific Journal of Mathematics is issued monthly as of January 1966. Regular subscription rate: $\$ 72.00$ a year (6 Vols., 12 issues). Special rate: $\$ 36.00$ a year to individual members of supporting institutions.

Subscriptions, orders for back numbers, and changes of address should be sent to Pacific Journal of Mathematics, 103 Highland Boulevard, Berkeley, California, 94708.

PUBLISHED BY PACIFIC JOURNAL OF MATHEMATICS, A NON-PROFIT CORPORATION

Printed at Kokusai Bunken Insatsusha (International Academic Printing Co., Ltd.), 8-8, 3-chome, Takadanobaba, Shinjuku-ku, Tokyo 160, Japan. 


\section{Pacific Journal of Mathematics \\ Vol. 65, No. $2 \quad$ October, 1976}

Andrew Adler, Weak homomorphisms and invariants: an example .......... 293

Howard Anton and William J. Pervin, Separation axioms and metric-like

functions ............................................. 299

Ron C. Blei, Sidon partitions and p-Sidon sets .................... 307

T. J. Cheatham and J. R. Smith, Regular and semisimple modules ........... 315

Charles Edward Cleaver, Packing spheres in Orlicz spaces .............. 325

Le Baron O. Ferguson and Michael D. Rusk, Korovkin sets for an operator on a

space of continuous functions ............................. 337

Rudolf Fritsch, An approximation theorem for maps into Kan fibrations ....... 347

David Sexton Gilliam, Geometry and the Radon-Nikodym theorem in strict

Mackey convergence spaces .................................

William Hery, Maximal ideals in algebras of topological algebra valued

functions ...................................... 365

Alan Hopenwasser, The radical of a reflexive operator algebra ........... 375

Bruno Kramm, A characterization of Riemann algebras................. 393

Peter K. F. Kuhfittig, Fixed points of locally contractive and nonexpansive

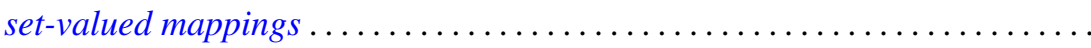

Stephen Allan McGrath, On almost everywhere convergence of Abel means of

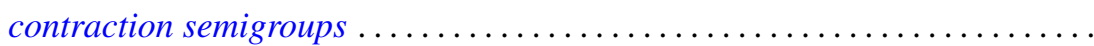

Edward Peter Merkes and Marion Wetzel, A geometric characterization of

indeterminate moment sequences............................ 409

John C. Morgan, II, The absolute Baire property ................... 421

Eli Aaron Passow and John A. Roulier, Negative theorems on generalized convex approximation .................................... 437

Louis Jackson Ratliff, Jr., A theorem on prime divisors of zero and characterizations of unmixed local domains ..............

Ellen Elizabeth Reed, A class of $T_{1}$-compactifications................... 471

Maxwell Alexander Rosenlicht, On Liouville's theory of elementary

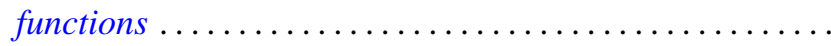

Arthur Argyle Sagle, Power-associative algebras and Riemannian

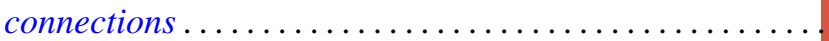

Chester Cornelius Seabury, On extending regular holomorphic maps from Stein manifolds...

Elias Sai Wan Shiu, Commutators and numerical ranges of powers of operators ...................................

Donald Mark Topkis, The structure of sublattices of the product of $n$ lattices ... 525

John Bason Wagoner, Delooping the continuous $K$-theory of a valuation

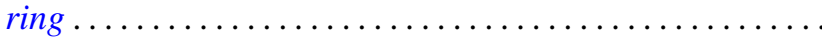

Ronson Joseph Warne, Standard regular semigroups...........

Anthony William Wickstead, The centraliser of $E \otimes_{\lambda} F \ldots$. 